\title{
PENs in the PENis: a case report and brief review of the literature
}

\author{
Vasileios Bonatsos ${ }^{*}$ (D) and Deepak Batura
}

\begin{abstract}
Background: According to the literature, there have been reports of introduction of foreign bodies into the urethra predominantly in males, both adults and children. Erotic stimulation, intoxication, assault and psychiatric conditions are the most frequent contributors.

Case presentation: A 70-year-old male presented with difficulty in passing urine for one week after having inserted two plastic ballpoint pens into his urethra. The patient had a failed attempt at removal using a rigid cystoscope and biopsy forceps. A Liga-clip applicator allowed successful blind removal of both pens while the patient was under a general anaesthetic.

Conclusions: Removal of urethral foreign bodies can be challenging as endoscopic removal may fail, and open or blind procedures may be required. Moreover, complications can be significant. On occasions, improvisations in techniques may be helpful, such as in our patient. A psychiatric review is vital to try and ensure the prevention of repeat incidents.
\end{abstract}

Keywords: Urethral foreign bodies, Urethral trauma, Polyembolokoilamania, Liga-clip

\section{Background}

Foreign body in the urethra is an infrequent urological emergency in the UK which can often be delayed in presentation and diagnosis, with variable management options and significant complications. We are the first to report the successful use of a Liga-clip applicator for removal of a urethral foreign body. This should inform urologists in their practice across the globe should they face a similar case in the future, especially in settings where appropriate or special instruments are not available but more importantly when other more common approaches fail.

\section{Case presentation}

A 70-year-old gentleman presented to the emergency department after manually inserting two pens in his urethra one week before. He had performed this act multiple

*Correspondence: vasileios.bonatsos1@nhs.net

Urology SpR, London North West Healthcare NHS Trust, Flat 42 Jefferson House, 33 Park Lodge Avenue, West Drayton, Greater London UB7 9FL, UK times in the past as a means of sexual gratification. Previously he was able to remove them himself, but could not on this occasion. He had developed a swelling of the penoscrotal area, with significant lower urinary tract symptoms (LUTS) and difficulty in emptying his urinary bladder (gradually rising post-void residual volumes of urine of $250 \mathrm{mls}$ and above on serial bedside bladder scans). A plain X-ray of the penoscrotal area confirmed the radio-opaque parts of the two pens lying inside the urethra (Fig. 1).

The patient had multiple comorbidities (atrial fibrillation-on rivaroxaban - which required reversing, raised body mass index (BMI), non-insulin-dependent diabetes mellitus (NIDDM), bilateral chronic leg lymphoedema, hypertension and hyperlipidaemia). After optimisation, we attempted a rigid urethroscopy under general anaesthesia as patient would not tolerate a local anaesthetic approach. At urethroscopy, the pens were seen in the urethra, with their distal end at approximately $2-3 \mathrm{~cm}$ from the urethral meatus (Fig. 2). However, the pens could not be grasped with a bladder biopsy forceps as 


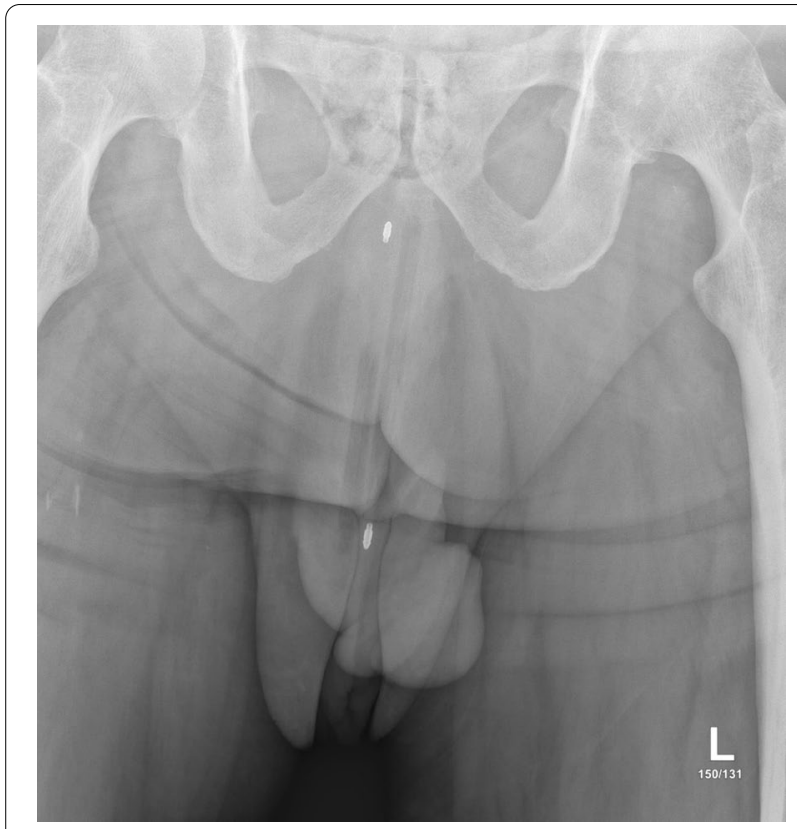

Fig. $1 \mathrm{X}$-ray of the penoscrotal region shows the radiopaque parts of the foreign bodies

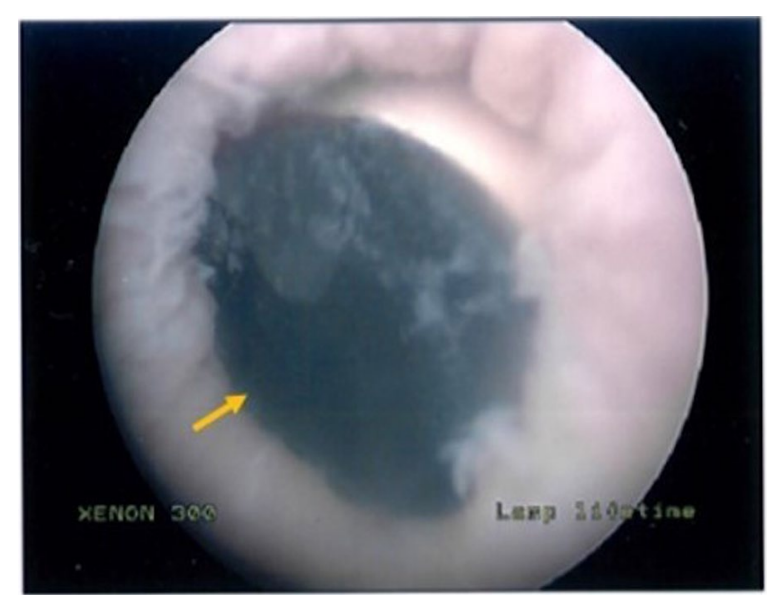

Fig. 2 Urethroscopy before the removal of the foreign bodies

the diameter of the pens was too large (approx. $6 \mathrm{~mm}$ each when measured post-removal). We are not aware/ nor had available grasping endoscopic forceps that could accommodate this size. Two options remained; either attempt a blind removal or perform a urethrotomy. A decision was made to attempt blind removal with long forceps or a grasper that would fit through the meatus. A Liga-clip applicator (Ethicon endosurgery, USA) was chosen and inserted into the urethra with its jaws closed (Fig. 3). The jaws were carefully opened around the pens, and after multiple attempts with simultaneous use of

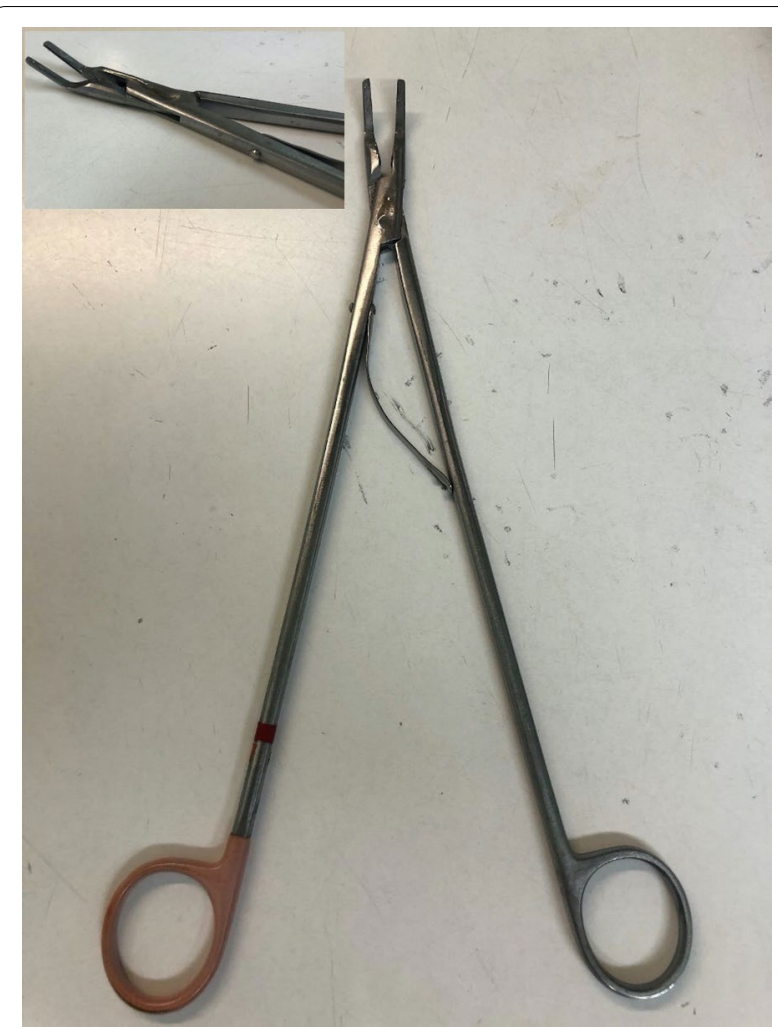

Fig. 3 Liga-clip applicator which was used for the removal of the foreign bodies

external urethral and digital rectal pressure to ensure the foreign bodies (FB) did not migrate into the urinary bladder, the pens were extracted one at a time (Fig. 4).

\section{Outcome and follow-up}

After the successful removal of the FBs, a completion cystourethroscopy was performed to check the urethra and the urinary bladder. This revealed no significant injury to the urethra, prostatic fossa or the urinary bladder. There was only some degree of urothelial inflammation due to the presence of the FB for several days (Fig. 5). A $16 \mathrm{Fr}$ silicone urinary catheter was inserted to relieve the urethra till the swelling from the instrumentation resolved. The patient was discharged home after a few days stay post-operatively when he had fully recovered from the general anaesthetic procedure and completed the intravenous antibiotic course given his high risk of urinary tract infections. He attended a successful trial without catheter outpatient appointment two weeks later. Subsequently, he was reviewed at the urology outpatient clinic a few months later. He was symptom free and had a normal uroflowmetry at the time. No further hospital investigations or acute management was required. The patient was discharged to the care of his general practitioner 


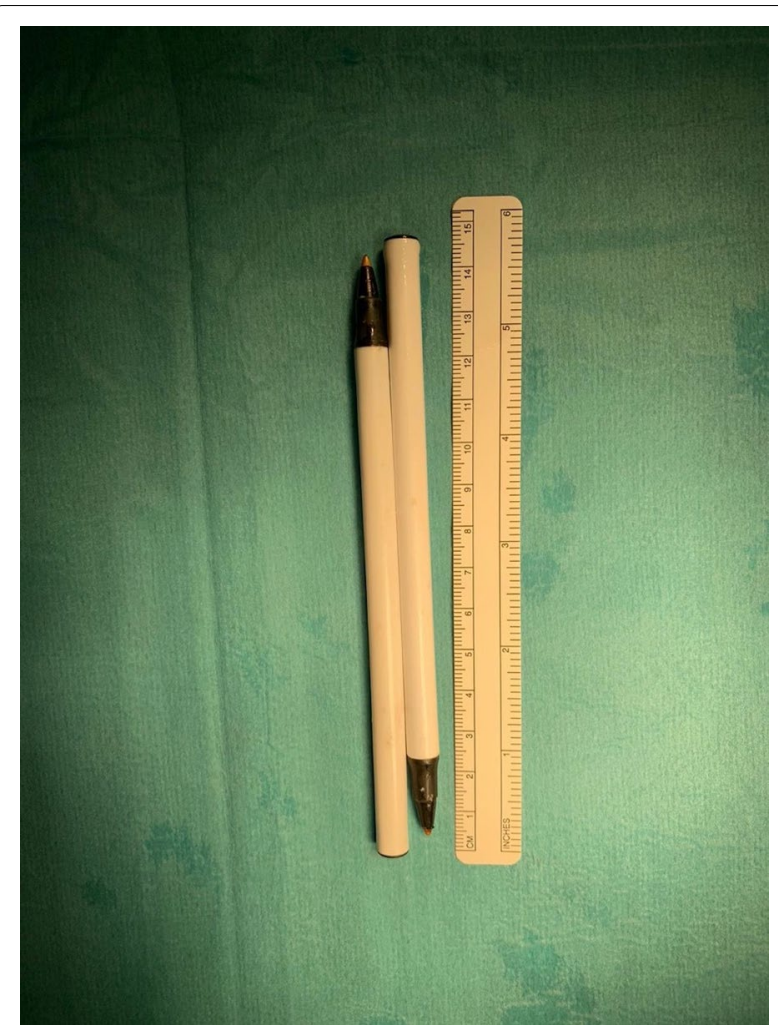

Fig. 4 Retrieved pens from the urethra

with advice to monitor his LUTS and refer him back if becomes symptomatic again in the future as we acknowledge that some complications such as urethral strictures can occur several months later. Also his general practitioner was asked to refer the patient for a psychiatric/ mental health review in the community to explore causes for the insertion of foreign bodies and prevent further incidents.

\section{Discussion}

"Polyembolokoilamania" derives from the Greek language and is the act of inserting foreign bodies (FB) into various body orifices. With regard to the urinary tract, there are case reports of insertion of a large variety of objects [1, 2]. Reports are more common in males, both children and adults, and also in those with psychiatric disorders [3]. Objects inserted include forks, pencils, pens, cables, wires, needles, scissors, bullets, magnets, tongue cleaners and even olive seeds (Table 1). The usual motives are for auto-erotic stimulation, erectile enhancement, attention-seeking, sexual curiosity, intoxication, assault or symptom control. There are iatrogenic causes of foreign bodies in the urethra such as migrated brachytherapy seeds, cut tips of Foley catheters or even Hem-olock clips (Table 1).
Most patients feel uncomfortable about reporting self-inserted FB and present late when complications such as infection, swelling, bleeding or urinary retention are setting in. Careful history taking and a thorough physical examination are vital. Symptoms vary, from a complete absence of indicators to abdominal pain, urinary retention, pus discharge, penile swelling and haematuria. If the history is uncertain and the physical examination is unclear whether the foreign body is still in the urethra, simple adjuncts such as a pelvic X-ray can be useful. However, in more complex cases, a urethrogram, ultrasonogram or computerised tomography $(\mathrm{CT})$ of the abdomen and pelvis may be required to identify the shape, size and exact location of the FB. These details are necessary to plan the appropriate technique for its removal (Table 1).

The definitive management includes the complete removal of the FB (intact or piecemeal) and dealing with the short- or long-term complications that may have occurred. Management should also include psychiatric evaluation of the circumstances that led to insertion for prevention of repeat episodes. There are several techniques for the extraction of a urethral FB. Blind removal is the most straightforward approach if the circumstances allow (i.e. foreign body protruding through meatus or visible in the distal urethra), or with simple manoeuvres and pressure on the penis, FBs can be pushed out.

The use of special long forceps can assist. Even the use of Hartmann ear forceps has been reported [4]. If this has failed or not indicated, cystourethroscopic removal is the next option. Removal can be via a flexible cystoscope with the use of biopsy forceps to attempt pulling the foreign body. A rigid cystoscope and patient under general anaesthesia or spinal anaesthesia allows better manipulation and ensures the best chances for this approach to be successful. This approach has the advantage of minimising urothelial trauma as it is done under direct vision, and at the same time, it allows assessment for any mucosal injury or thickening. If both these options have failed, an open procedure is the last resort.

Open procedures depend on the location and nature of the FB. These may include meatotomy, urethrotomy and even cystotomy if the FB has been pushed into the bladder or is long enough to reach it. This route is more invasive but ensures successful removal of the foreign body in all challenging cases. These procedures should be accompanied by a urethral or suprapubic catheter to allow the urethra or the bladder to heal (Table 1). In our patient, instruments such as haemostats did not provide sufficient grip and traction because of the long-term impaction of the FBs and we had to use a sturdier instrument-the Liga-clip applicator. 

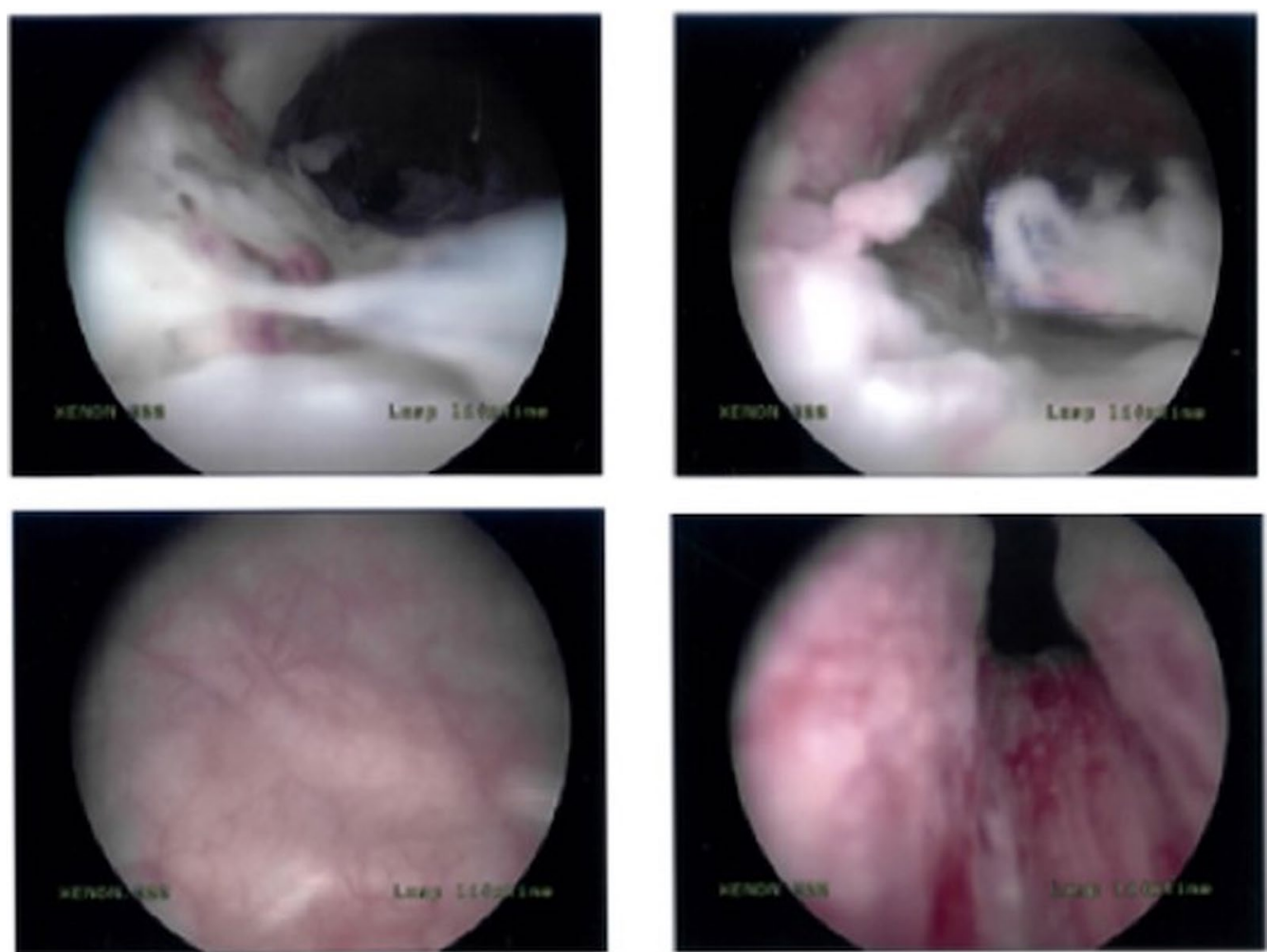

Fig. 5 Urethroscopy after the removal of the foreign bodies showing degree of urothelial inflammation

Although not common, the removal of a urethral foreign body can be challenging. As describing in our case, a urologist should be prepared to use multiple approaches and make use of available instruments, be innovative and patient until a successful outcome is achieved. In our case, this required good coordination with the anaesthetic team, pre-operative patient optimisation, involvement of the emergency theatre staff and also postdischarge alert of patient's GP as well as community psychiatry team.

\section{Conclusions}

- Foreign body in the urethra is an infrequent urological emergency. Reasons for insertion of urethral foreign bodies include sexual stimulation, assault, intoxication, LUTS, psychiatric pathologies.
- Imaging studies like ultrasonogram, penoscrotal X-ray, urethrogram or even CT scan of the abdomen and pelvis are useful to locate the foreign body and identify its shape, size and relations.

- Presenting symptoms include dysuria, gross haematuria, urinary retention, urinary tract infections, penile discharge, frequent urination, decreased urine volume and painful erection.

- Approaches to remove the urethral foreign bodies are blind techniques, cystoscopic or open procedures. Post-removal complications include urethral strictures, false passages, fistulas, infections, even bladder perforations.

On occasion, the surgeon has to improvise and make use of innovative instruments, especially in resource limited settings or in emergency. 
Table 1 Summary of urethral foreign bodies cases according to the available literature (items used, reasons for insertion, presenting symptoms, removal techniques and post-removal complications)

\begin{tabular}{|c|c|c|c|c|}
\hline Items used & Reasons for insertion & Presenting symptoms & Removal techniques & Post-removal complications \\
\hline Forks $[1,4,5]$ & Self-stimulation $[1,4,5]$ & Dysuria $[1,4,5]$ & $\begin{array}{l}\text { Manual extraction with } \\
\text { extrinsic pressure }[1,4,5]\end{array}$ & $\begin{array}{l}\text { Urinary tract infection sepsis } \\
{[1,4,5]}\end{array}$ \\
\hline Spoons $[1,4,5]$ & $\begin{array}{l}\text { Erectile enhancement [1, } \\
4,5]\end{array}$ & Gross haematuria $[1,4,5]$ & Endoscopic retrieval $[1,4,5]$ & Urethral false passage $[1,4,5]$ \\
\hline Metal screws $[1,4,5]$ & Attention seeking $[1,4,5]$ & Urinary retention & Meatotomy $[1,4,5]$ & Lacerations $[1,4,5]$ \\
\hline Pieces of cardboard $[1,4,5]$ & $\begin{array}{l}\text { Result of erotic impulses } \\
{[1,4,5]}\end{array}$ & $\begin{array}{l}\text { Urinary tract infections [1, } \\
4,5]\end{array}$ & Urethrotomy $[1,4,5]$ & Stricture formation $[1,4,5]$ \\
\hline Staples $[1,4,5]$ & $\begin{array}{l}\text { Psychometric problems [1, } \\
4,5]\end{array}$ & Penile discharge $[1,4,5]$ & Cystotomy $[1,4,5]$ & Urethral Defect [2] \\
\hline $\begin{array}{l}\text { Writing utensils such as } \\
\text { pens and pencils }[1,4,5]\end{array}$ & $\begin{array}{l}\text { Sexual curiosity, or sexual } \\
\text { practice while intoxicated } \\
{[1,4,5]}\end{array}$ & Frequent urination & $\begin{array}{l}\text { Voiding to expel the for- } \\
\text { eign body }[1,4,5]\end{array}$ & Fournier's gangrene \\
\hline Coaxial cable $[1,4,5]$ & $\begin{array}{l}\text { Relieving urinary symptoms } \\
\text { (LUTS/retention) }\end{array}$ & Decreased urine volume & & Bladder perforation \\
\hline Spray foam sealant $[1,4,5]$ & Senility, intoxication & Painful erection & & Urethral fistulas [4] \\
\hline Medical needles & act of physical abuse & & & \\
\hline \multicolumn{5}{|l|}{ Household pipes } \\
\hline \multicolumn{5}{|l|}{ Sewing needles } \\
\hline \multicolumn{5}{|l|}{ Nail Scissors } \\
\hline \multicolumn{5}{|l|}{ Knotted electric wires } \\
\hline \multicolumn{5}{|l|}{ Pocket batteries } \\
\hline \multicolumn{5}{|l|}{ Little fish } \\
\hline \multicolumn{5}{|l|}{ Pen tips } \\
\hline \multicolumn{5}{|l|}{ Small magnetic balls } \\
\hline \multicolumn{5}{|l|}{ Olive seeds } \\
\hline \multicolumn{5}{|l|}{ 'Corn-on-the-cob'skewers } \\
\hline \multicolumn{5}{|l|}{ Bullets } \\
\hline \multicolumn{5}{|l|}{ Safety pins } \\
\hline \multicolumn{5}{|l|}{ Rubber tube } \\
\hline \multicolumn{5}{|l|}{ Glass ampoules } \\
\hline \multicolumn{5}{|l|}{ Metallic screws } \\
\hline \multicolumn{5}{|l|}{ Brachytherapy seeds } \\
\hline \multicolumn{5}{|l|}{ Cut end of Foley catheters } \\
\hline \multicolumn{5}{|l|}{ Sexual vibrators } \\
\hline \multicolumn{5}{|l|}{ Hem-o-lock clips } \\
\hline \multicolumn{5}{|l|}{ Superglue } \\
\hline \multicolumn{5}{|l|}{ Tongue cleaners } \\
\hline Transistor radio antennas & & & & \\
\hline
\end{tabular}

\section{Abbreviations}

UK: United Kingdom; LUTS: Lower urinary tract symptoms; BMI: Body mass index; NIIDM: Non-insulin-dependent diabetes mellitus; FB: Foreign body; USA: United States of America; CT: Computerised tomography; GP: Genera practitioner.

\section{Acknowledgements}

Not applicable.

\section{Authors' contributions}

VB is the major contributor in conception, analysis and interpretation of the data involved in this case report. He was involved in draft writing and revision of this case report. DB contributed in the preparation, review of the manuscript and final approval of the submitted version. All authors have read and approved the manuscript.

\section{Funding}

There was no funding required for this case report. 
Availability of data and material

Patient's electronic and paper records.

\section{Declarations}

Ethics approval and consent to participate

No ethics approval required for this case report.

\section{Consent for publication}

Written informed consent to publish this information was obtained from study participant.

\section{Competing interests}

Authors have no conflict of interest to declare.

Received: 30 March 2021 Accepted: 31 May 2021

Published online: 08 June 2021

\section{References}

1. Palmer CJ, Houlihan M, Psutka SP, Ellis KA, Vidal P, Hollowell CM (2016) Urethral foreign bodies: clinical presentation and management. Urology 97:257-260

2. Simms A, Chappidi M, Yang H, Hampson L, Breyer B, Coher A (2020) Urethral defect in setting of recurrent urethral foreign body insertion. Urology 137:e12-e13

3. Rodríguez D, Thirumavalavan N, Pan S, Apoj M, Butaney M, Gross M et al (2019) Epidemiology of genitourinary foreign bodies in the United States emergency room setting and its association with mental health disorders. Int J Impot Res 32:426-433

4. Iwamoto T, Hosokawa Y, Otsuka K, Matsushita C, Hayashi Y, Onishi K et al (2016) Urethral fistula caused by an urethrovesical foreign body: a case report. Hinyokika Kiyo 62(7):373-376

5. Naidu K, Chung A, Mulcahy M (2013) An unusual urethral foreign body. Int J Surg Case Rep 4(11):1052-1054

\section{Submit your manuscript to a SpringerOpen ${ }^{\circ}$ journal and benefit from:}

- Convenient online submission

- Rigorous peer review

- Open access: articles freely available online

- High visibility within the field

- Retaining the copyright to your article 